\title{
Hepatitis E virus seroprevalence among the general population in a livestock-dense area in the Netherlands: a cross-sectional population-based serological survey
}

Arianne B. van Gageldonk-Lafeber ${ }^{1 *}$, Wim van der Hoek ${ }^{1}$, Floor Borlée ${ }^{2,3}$, Dick J. J. Heederik², Sofie H. Mooi ${ }^{1}$, Catharina B. M. Maassen ${ }^{1}$, C. Joris Yzermans ${ }^{3}$, Barry Rockx ${ }^{1}$, Lidwien A. M. Smit ${ }^{2}$ and Johan H. J. Reimerink ${ }^{1}$

\begin{abstract}
Background: Recent serological studies indicate that hepatitis E virus (HEV) is endemic in industrialised countries. The increasing trend in the number of autochthonous cases of HEV genotype 3 in Western European countries, stresses the importance to get insight in the exact routes of exposure. Pigs are the main animal reservoir, and zoonotic food-borne transmission of HEV is proven. However, infected pigs can excrete large amounts of virus via their faeces enabling environmental transmission of HEV to humans. This might pose a risk for of neighbouring residents of livestock farming.

Methods: Within a large study on the health of people living in the vicinity of livestock farming we performed a cross-sectional population-based serological survey among 2,494 non-farming adults from the general population in a livestock-dense area in the south of the Netherlands. Participants completed risk factor questionnaires and blood samples of 2,422 subjects (median age 58 years, range 20-72) were tested for anti-HEV IgG using an enzyme immune assay (Wantai). The aim of this study was to determine the HEV seroprevalence and to assess whether seropositivity in adults was associated with living in the vicinity of pig farms.

Results: The average seroprevalence of HEV was $28.7 \%$ (95\% Cl: 26.9-30.5). Determinants associated with an increased risk for HEV seropositivity were male gender and low level of education. There was a clear trend of increasing prevalence with increasing age (Chi-square test for linear trend, $X^{2}=83.1 ; p<0.001$ ). A high number of pigs within 1,000 $\mathrm{m}$ of the residential address was not a risk factor for seropositivity.

Conclusions: This study confirmed the high HEV seroprevalence (29\%) in the general population of the Netherlands, but presence of antibodies was not associated with residential proximity to pig farms. The prevalence increased with age from 10\% in adolescents to 33\% among those aged 50 and above, supporting the assumption of a cumulative lifetime exposure to HEV in the Netherlands as well as a higher infection pressure in the past. Our findings cannot refute the assumption that transmission is primarily food-borne.
\end{abstract}

Keywords: Hepatitis E virus, Environmental exposure, Livestock, Seroprevalence, Zoonoses

\footnotetext{
* Correspondence: rianne.van.gageldonk@rivm.nl

${ }^{1}$ National Institute for Public Health and the Environment (RIVM), Bilthoven,

The Netherlands

Full list of author information is available at the end of the article
} 


\section{Background}

Hepatitis E virus (HEV) is a major cause of enterically transmitted hepatitis, especially in developing countries. However, recent studies show that autochthonous HEV infections are an increasing public health concern in industrialised countries [1-12].

The most common clinical presentation of HEV infection is acute hepatitis. Usually this is a self-limiting disease, with jaundice as the most common symptom $[4,13-15]$. In patients with pre-existing liver disease and immunosuppressed patients, the clinical course of disease is often more severe and in developing countries excess mortality is seen in pregnant women $[8,10,14-16]$. However, most HEV infections in industrialised countries are either unrecognised or asymptomatic $[1,14,16,17]$. This is supported by recent serological studies in several European countries, showing that the anti-HEV IgG seroprevalence in healthy blood donors varied between 7 and $52 \%$, depending on both geographical area and the antibody assay used [17-22].

$\mathrm{HEV}$ is a non-enveloped single-stranded RNA virus belonging to the Hepeviridae family [16, 17, 23]. Four major genotypes, within species Orthohepevirus $A$, can infect humans $[10,15,23,24]$. The genotypes 1 and 2 are restricted to human beings, and the genotypes 3 and 4 can infect both human beings and mammals. HEV-1 and HEV-2 are endemic in developing countries, leading to sporadic cases as well as large outbreaks. HEV-3 and HEV-4 are responsible for an increasing number of autochthonous hepatitis E infections worldwide $[4,10,16$, $17,25]$. The more recently discovered HEV genotypes 5 and 6 are so far only detected in animals, while genotype 7 is also described in humans [10, 26-29].

In contrast to HEV-1 and HEV-2, for which the faecaloral transmission route via contaminated water has been confirmed, the transmission routes of HEV-3 and HEV-4 are largely unclear and the exact source of infection remains unknown for the majority of patients $[4,17,27,28]$. The increasing trend in the number of autochthonous cases in Western European countries stresses the importance to get insight in the route of infection, enabling the implementation of control measures against human HEV infections [27, 28, 30].

It is hypothesized that HEV-3 and HEV-4 have a zoonotic origin, supported by the high prevalence of HEV-3 and HEV-4 among domestic pigs and wild boars $[23,26,31]$. In the Netherlands, the prevalence rate of HEV-3 in the domestic pig population is estimated at $55 \%$, and domestic pigs may therefore be an important reservoir for human HEV infections [28, 32]. Furthermore, the frequent detection of HEV in pork products and the high similarity between porcine and human HEV sequences suggest zoonotic transmission of HEV-3 and HEV-4 worldwide [33-36]. Zoonotic food-borne transmission has been proven by the identification of identical nucleotide sequences in autochthonous HEV patients and in leftover portions of consumed contaminated food [37-40]. But zoonotic $\mathrm{HEV}$ transmission might also occur through exposure to contaminated environments. Infected pigs, which are generally asymptomatic, can excrete large amounts of virus via their faeces in the environment. This may lead to human infections [26-28, 41]. The high anti-HEV serum antibody rates in humans with occupational contact with pigs, like farmers and veterinarians, provide indirect evidence for this route of transmission [42-47]. However, environmental exposure to HEV might also pose a risk for of neighbouring residents of livestock farming, as was the case during the major Dutch Q-fever outbreak in 2007-2010 [48].

In the Netherlands there is an ongoing debate on the environmental health risks as a result of (intensive) livestock farming in areas highly populated with both livestock and people. At a surface of approximately $34.000 \mathrm{~km}^{2}$ almost 17 million people are living together with 75 million chickens, 7 million pigs, 4 million cattle and 1.5 million goats and sheep. Within a large study on the health of people living in the vicinity of livestock farming, we performed a serological survey in order to assess the HEV seroprevalence among non-farming adults from the general population in a livestock-dense area in the south of the Netherlands. Furthermore, we investigated whether living close to pig farms is a risk factor for HEV seropositivity, focusing on the role of environmental transmission of HEV from pig farms to residents living in the vicinity of these farms.

\section{Methods}

In 2014 the Livestock Farming and Neighbouring Residents' Health study (Dutch acronym: VGO) started, aiming to assess the relationship between livestock farming and a number of health outcomes in people living in the eastern part of the province of Noord-Brabant and the northern part of the province of Limburg. This part of the Netherlands is a relatively highly populated rural area with a high density of livestock farms. Within the VGO study a cross-sectional health study was performed, investigating three categories of health effects: 1) respiratory health effects, 2) livestock-associated infections, and 3) carriage of resistant microorganisms. Furthermore, air sampling was conducted in order to assess to what extent residents living in the vicinity of livestock farms were exposed to emissions of these farms, including endotoxin amount, PM10 and DNA of Staphylococcus aureus and E. coli. Participants of the cross-sectional health study provided blood samples in order to assess (previous) exposure to several livestock-farming associated pathogens, including HEV. 


\section{Study population}

The study population was selected in a two-step procedure. First, a questionnaire survey was conducted among 14,163 unrelated adults from the general population (aged 18-70 years) living in the study area. Participants were recruited via their general practitioner (GP). In the Netherlands each individual is registered with just one general practice, mostly close to residential address. Predefined inclusion criteria have been described previously by Borlée et al. [49]. Second, questionnaire participants who gave consent to be contacted for further studies, and who were not working or living on a farm, were eligible for the serological survey $(n=8,714)$ [50]. Based on their home addresses, twelve temporary study centres were established. Figure 1 shows the location of the temporary study centres, and pig density in the Netherlands in 2014. All participants living within a distance of approximately $10 \mathrm{~km}$ of a temporary study centre $(n=7,180)$ were invited to the nearest centre for a medical examination, including blood sampling for serological analyses against livestock-associated pathogens. Furthermore, they were asked to fill in a questionnaire comprising items on symptoms and diseases, home characteristics, smoking habits, education, profession, leisure activities, dietary habits (including the consumption of pork meat), and animal contact, including exposure to animal farm environment during childhood. Data were collected between 10 March 2014 and 27 February 2015. Patients' privacy was ensured as described earlier [49-51]. In short, medical information and address records were kept separated at all times by using a Trusted Third Party (Stichting Informatie Voorziening Zorg, Houten). The VGO study protocol was approved by the Medical Ethical Committee of the University Medical Centre Utrecht. All participants signed informed consent.

\section{Exposure from livestock farms}

Based on the home address of each participant, several exposure variables were computed, including distance to the nearest pig farm with more than 25 pigs and the total number of pigs within $1,000 \mathrm{~m}$ [52]. Information on farm characteristics in the study area was derived from the provincial database of mandatory environmental licenses for keeping livestock for 2012. This database contains amongst others data on number and type of animals and geographic coordinates of farms (specific for type of livestock).

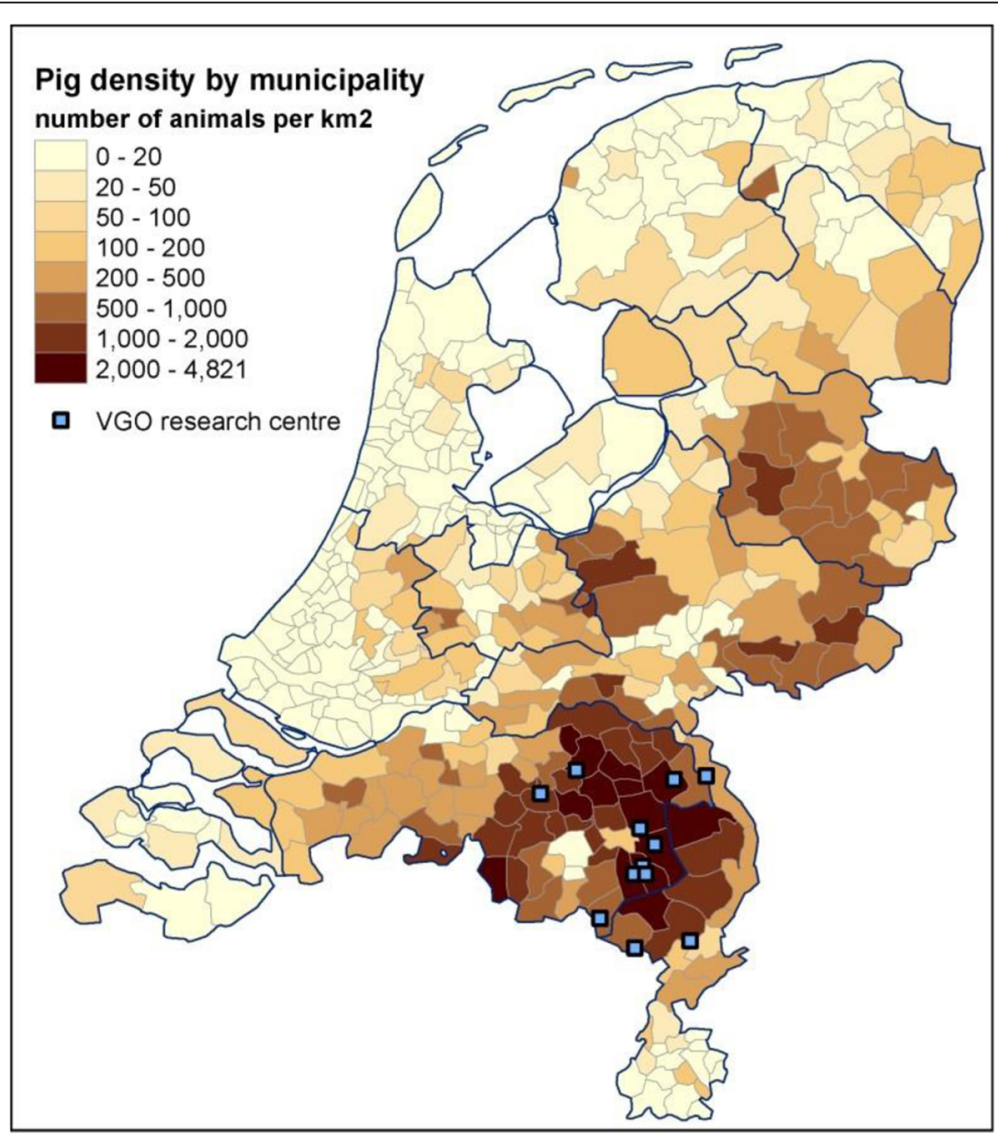

Fig. 1 Location of temporary study centres in relation to pig density in the Netherlands in 2014 (Source: Statistics Netherlands) 


\section{Serological analyses}

Sera were analysed at the National Institute for Public Health and the Environment (RIVM) for the presence of IgG antibodies against HEV, using a commercial anti-HEV IgG enzyme immune assay (Wantai Biological Pharmacy Enterprise Co,. Ltd., Beijing, China). The test was performed according to the instructions of the manufacturer. Samples with anti-HEV IgG ratio $<0.90$ were considered negative, those with ratio $>=0.90$ but $<1.10$ were defined as borderline, and samples with ratio $>=1.10$ were considered as positive.

\section{Statistical analyses}

Seroprevalence, defined as the percentage of participants with borderline or positive anti-HEV IgG ratio, and 95\% confidence intervals $(\mathrm{CI})$ were calculated for the overall study population, per age group and per study centre.

Logistic regression analysis was performed to study potential determinants for HEV seropositivity. The following variables were included in the univariate analysis: age, gender, educational level, country of birth, consumption of pork meat, smoking status, spending childhood in the study region or on a (pig) farm, performing jobs on a farm during childhood, contact with animals during work or study, keeping farm animals and/or pigs for a hobby in the last 5 years, spending time abroad during the last 12 months, visiting a farm in the last 12 months (with or without contact with pigs during that visit) and the numbers of pigs within $1.000 \mathrm{~m}$ of the residential address of the participants. All variables with a $P$-value $<=0.2$ in the univariate analyses were included in the multivariate logistic regression model. Adjusted odds ratios (ORs) and 95\% CIs were calculated and a $P$ value $<0.05$ was used to determine significance. $T$ rend in seroprevalence with increasing age was tested with the Mantel-Haenszel chi square for linear trend.

Median distance from home address to nearest farm with more than 25 pigs was compared between participants with positive or borderline and those with negative anti-HEV IgG ratio using Mann-Whitney $U$ test. This analysis was stratified by six age groups: $20-29,30-39$, $40-49,50-59,60-69$ and 70 years and older.

The random forest method (46) was used to determine the ability of the potential risk factors to predict the anti-HEV IgG ratio or the infection status. Unlike regression, the random forest requires no underlying assumptions about the functional form of the model or distribution of the data and provides a reliable assessment of the contribution of the predictor variables to generate predictions of an outcome. The algorithm predicts the outcome (e.g. antiHEV IgG ratio) of an individual based upon the individual's predictor variables, quantifies the prediction accuracy by means of estimates such as the mean square error (or proportion of correct classifications/statuses when predicting the status of an individual) and proportion of explained variance, and ranks the predictor variables according to their relative importance. Relative importance of a predictor variable is calculated by randomly permuting the data for that variable (leaving all other data unchanged) and comparing the prediction accuracy obtained with the 'shuffled' data set with that of the original data set. If the variable has little bearing on prediction, the mean square error will remain about the same after shuffling, while if the variable is useful for prediction the mean square error will deteriorate. The increase in mean square error that results from the shuffling is then a measure of variable importance which is used to rank the predictor variables.

Analyses were performed using SAS 9.3 and R version 3.1.0 (Random forest).

\section{Results}

A total of 2,494 of the 7,180 invited persons participated in the cross sectional serological survey, (response rate $=$ $34.7 \%)$. Serum samples were available for 2,422 participants (97.1\%). The primary reason for missing serumsamples was failure to collect enough blood for analysis. The median age of the participants, from whom a sample was available, was 58 years (range: $20-72$ years) and $45.6 \%$ was male (Table 1). Although there were some differences between responders and non-responders, a non-response analysis within the initial questionnaire survey comparing the electronical medical records of the subjects recruited via GPs, showed that these differences do not affect the relationship between health and the presence of livestock [53]. A total of 2,163 of the 2,422 participants (89.3\%) resided in the province of Brabant and Limburg during childhood, of which 1,816 (84.0\%) lived in the specific study region. On average, the participants have lived at their current residential address for 20 years (standard deviation 13.5 years). The number of pigs within $1,000 \mathrm{~m}$ of the residential address varied between 0 and 79,057 (median $=2,701$; interquartile range: $336-9,035)$ and the distance to the nearest pig farm with more than 25 pigs ranged from 11 to $2500 \mathrm{~m}$ (median $=687 \mathrm{~m}$; interquartile range: 462-932).

Positive and borderline positive anti-HEV IgG ratio was found for respectively $666(27.5 \%)$ and $29(1.2 \%)$ of the 2,422 participants. Overall seroprevalence was $28.7 \%$ (95\% CI: 26.9-30.5; Table 1), ranging between study centres from $16.7 \%$ (95\% CI: $8.1-25.3$ ) to $35.7 \%$ (95\% CI: 25.5-46.0). Seroprevalence increased with age (Fig. 2).

Multivariate logistic regression analysis showed an increased risk for HEV seropositivity in participants aged 50 years or older, male participants and participants who reported a low level of education (Table 2). There was a clear trend of increasing prevalence with increasing age (Chi-square test for linear trend, $\mathrm{X}^{2}=83.1 ; p<0.001$ ). A high number of pigs within $1,000 \mathrm{~m}$ of residential address 
Table 1 Density of pigs, details of study population and hepatitis E virus seroprevalence by study centre

\begin{tabular}{|c|c|c|c|c|c|c|c|}
\hline Study centre & Density of pigs ${ }^{a}$ & $\begin{array}{l}\text { Number of } \\
\text { participants }\end{array}$ & Median age (years) & Range (years) & Male participants (\%) & Seroprevalence ${ }^{\mathrm{b}}(\%)$ & {$[95 \% \mathrm{Cl}]^{\mathrm{C}}$} \\
\hline Afferden & 717 & 49 & 59.2 & {$[33.5-71.1]$} & 57.5 & 25.5 & {$[13.1-38.0]$} \\
\hline Asten $^{d}$ & 3,535 & 291 & 61.4 & {$[20.4-71.4]$} & 45.8 & 34.0 & {$[28.6-39.5]$} \\
\hline Bakel & 3,756 & 315 & 59.3 & {$[21.5-71.7]$} & 47.1 & 29.2 & {$[24.1-34.3]$} \\
\hline Boxtel & 988 & 170 & 59.3 & {$[24.8-71.6]$} & 45.0 & 27.2 & {$[20.5-33.9]$} \\
\hline Budel & 1,080 & 200 & 61.4 & {$[21.4-71.6]$} & 49.5 & 32.6 & {$[25.8-39.4]$} \\
\hline Deurne & 3,882 & 132 & 60.5 & {$[29.0-71.7]$} & 50.0 & 18.6 & [11.7-25.4] \\
\hline Heeswijk-Dinther & 3,812 & 375 & 57.5 & {$[20.1-71.4]$} & 37.1 & 30.1 & {$[25.5-34.8]$} \\
\hline Heusden $^{d}$ & 3,535 & 72 & 58.9 & {$[24.2-71.4]$} & 55.6 & 16.7 & {$[8.1-25.3]$} \\
\hline Horn & 1,268 & 85 & 57.1 & {$[24.0-71.7]$} & 45.2 & 35.7 & {$[25.5-46.0]$} \\
\hline Someren & 3,447 & 170 & 57.9 & {$[28.6-71.2]$} & 48.2 & 29.4 & {$[22.6-36.3]$} \\
\hline St. Anthonis & 4,460 & 399 & 57.0 & {$[22.6-71.8]$} & 44.5 & 26.9 & {$[22.4-31.4]$} \\
\hline Stramproy & 878 & 236 & 57.4 & [21.3-72.0] & 46.3 & 26.6 & [20.9-32.4] \\
\hline Total & 2,506 & 2,494 & 58.6 & [20.1-72.0] & 45.6 & 28.7 & [26.9-30.5] \\
\hline
\end{tabular}

${ }^{\mathrm{a}}$ Number of pigs per $\mathrm{km}^{2}$ by municipality, based on the provincial databases of mandatory environmental licenses for keeping livestock for 2012

${ }^{\mathrm{b}}$ Anti-HEV lgG ratio $>=0.90$

' $95 \%$ Confidence Interval

${ }^{\mathrm{d}}$ Asten and Heusden are both situated in the municipality Asten, and therefore have the same pig density

was not a risk factor. Other variables for exposure to pigs (e.g. number of pig farms or the presence of at least one pig farm within $1,000 \mathrm{~m}$ of residential address) gave similar results in both univariate and multivariate logistic regression analyses as number of pigs within $1,000 \mathrm{~m}$ of residential address (data not shown). Participants who reported to follow a diet without pork meat $(n=47)$ did not have a significantly lower risk for HEV seropositivity. Exclusion of the 29 samples with borderline positive anti-HEV IgG ratio did not affect the results of the of univariate and multivariate logistic regression analyses. This also holds when the borderline samples were considered as negative anti-HEV IgG ratio (data not shown).

Generally, seronegative participants lived closer to pig farms than seropositive participants. This difference was statistically significant for the overall group and for the age group 60-70 years (Table 3 ).

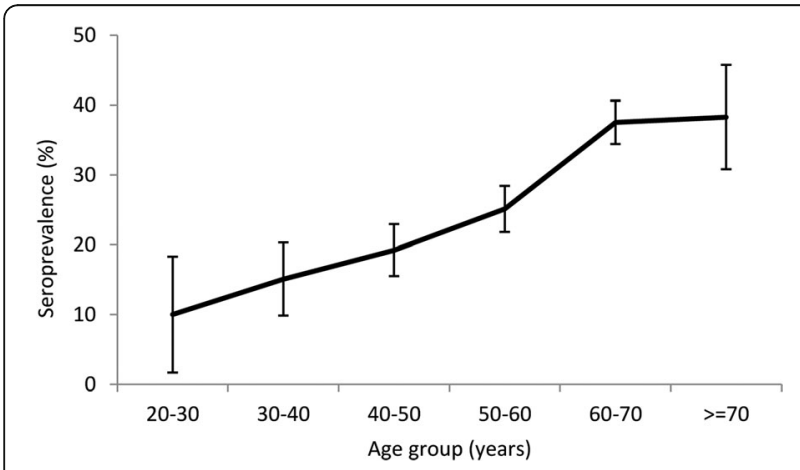

Fig. 2 Seroprevalence of antibodies against hepatitis E virus by age group
Despite the associations detected and reported above, the random forest method showed that the potential risk factors considered in this study are not at all able to predict anti-HEV IgG ratio nor disease status (results are omitted). Indeed, the proportion of explained variance was practically zero in our prediction analysis, which in particular prevents us from ranking the risk factors.

\section{Discussion}

The present population-based serological survey confirms the high HEV seroprevalence (29\%) in the general population of the Netherlands, but provides no evidence for environmental transmission from pig farms to humans living in the vicinity of these farms.

Comparison of the seroprevalence found in this study with results from other European countries is difficult because of considerable differences in the studied populations, as well as the used assay for HEV antibody testing [54-56]. Recent studies using sensitive assays (like the Wantai assay we used) reported HEV seroprevalence varying between $16 \%$ and $52 \%$ [18, 57-61]. Our seroprevalence $(29.7 \%)$ corresponds well with the $27 \%$ prevalence found in a large serological screening of Dutch blood donors [18]. Both studies used the Wantai assay to measure HEV specific IgG antibodies. In contrast, a population-based seroprevalence study in the general population in the Netherlands in 2006-2007, using a less sensitive assay for detection of prolonged IgG antibodies (MP Diagnostics, France), found a seroprevalence of only $3 \%$ [62]. Comparative studies suggest that the Wantai assay gives the most reliable estimate of the HEV seroprevalence, because it is more sensitive, it is positive 
Table 2 Hepatitis E virus seroprevalence in the general population and potential determinants for HEV seropositivity

\begin{tabular}{|c|c|c|c|c|c|c|}
\hline Determinants & $\mathrm{N}$ & Seroprevalence (\%) & Crude $O R^{b}$ & {$[95 \% \mathrm{Cl}]^{\mathrm{C}}$} & Adjusted $O R^{b, d, e}$ & {$\left[95 \% \mathrm{Cl}^{\mathrm{c}}\right.$} \\
\hline \multicolumn{7}{|l|}{ Age (years) } \\
\hline $20-30$ & 50 & 10.0 & Ref. & & Ref. & \\
\hline $30-40$ & 179 & 15.1 & 1.60 & {$[0.58-4.39]$} & 1.49 & {$[0.54-4.13]$} \\
\hline $40-50$ & 432 & 19.2 & 2.14 & {$[0.82-5.55]$} & 2.01 & {$[0.77-5.26]$} \\
\hline $50-60$ & 661 & 25.1 & 3.02 & [1.18-7.72] & 2.58 & {$[1.00-6.70]$} \\
\hline $60-70$ & 938 & 37.5 & 5.40 & {$[2.13-13.73]$} & 4.22 & {$[1.63-10.91]$} \\
\hline$>=70$ & 162 & 38.3 & 5.58 & {$[2.10-14.80]$} & 4.15 & {$[1.53-11.24$} \\
\hline
\end{tabular}

Gender

$\begin{array}{lll}\text { Female } & 1,318 & 25.6 \\ \text { Male } & 1,104 & 32.3\end{array}$

Ref.

Ref.

ducational level

\begin{tabular}{|c|c|c|c|c|c|c|}
\hline High & 733 & 24.8 & Ref. & & Ref. & \\
\hline Medium & 1,080 & 26.9 & 1.12 & [0.90-1.38] & 1.10 & [0.87-1.38] \\
\hline Low & 609 & 36.5 & 1.74 & [1.37-2.20] & 1.36 & [1.04-1.76] \\
\hline
\end{tabular}

Diet without pork meat

$\begin{array}{llll}\text { No } & 2,360 & 28.8 & \text { Re }\end{array}$

Ref. Ref.

Yes $\quad 47$

$\begin{array}{lll}0.59 & {[0.28-1.22]} & 0.72\end{array}$

Missing 15

Ever smoked

$\begin{array}{lll}\text { No } & 1,034 & 26.5 \\ \text { Yes } & 1,388 & 30.3\end{array}$

Ref.

Ref.

Childhood in study region

$\begin{array}{lll}\text { No } & 580 & 32.2 \\ \text { Yes } & 1,816 & 27.4 \\ \text { Missing } & 26 & \end{array}$

Ref.

Ref.

Missing

26

0.79

[0.65-0.97]

0.85

[0.68-1.07]

Childhood on pig farm

$\begin{array}{lllllll}\text { No } & 1,928 & 27.6 & \text { Ref. } & \text { Ref. } & & \\ \text { Yes } & 468 & 32.5 & 1.26 & {[1.02-1.57]} & 1.21 & {[0.94-1.55]} \\ \text { Missing } & 26 & & & & \end{array}$

Performed jobs on farm during childhood

\begin{tabular}{|c|c|c|c|c|c|c|}
\hline No & 1,090 & 26.9 & Ref. & - & Ref. & \\
\hline Yes & 1,220 & 29.7 & 1.15 & [0.96-1.38] & 1.02 & {$[0.83-1.27]$} \\
\hline Missing & 112 & & & & & \\
\hline \multicolumn{7}{|c|}{ Jumber of pigs within 1000 m of residential address (tertiles) } \\
\hline Low $^{f}$ & 807 & 32.1 & Ref. & & Ref. & \\
\hline Intermediate ${ }^{g}$ & 808 & 26.9 & 0.78 & {$[0.63-0.96]$} & 0.79 & [0.63-0.99] \\
\hline High $^{\text {h }}$ & 807 & 27.1 & 0.79 & {$[0.64-0.98]$} & 0.83 & {$[0.66-1.04]$} \\
\hline
\end{tabular}

Including both positive and borderline samples (anti-HEV IgG ratio > $=0.90$ )

bodds Ratio

'95\% Confidence Interval

${ }^{\mathrm{d}}$ ORs are adjusted for age, gender, educational level, diet without pork meat, ever smoked, childhood in study region, childhood on pig farm, jobs on farm during childhood and number of pigs within $1000 \mathrm{~m}$ of residential address

${ }^{\mathrm{e}}$ Adjusted ORs and $95 \%$ Cls were calculated for cases without missing answers $(N=2,301)$

f Number of pigs within $1000 \mathrm{~m}<=1,003$

${ }^{9}$ Number of pigs within $1000 \mathrm{~m}>1,003$ and $<=5,771$

${ }^{\mathrm{h}}$ Number of pigs within $1000 \mathrm{~m}>5,771$ 
Table 3 Median distance from home address to nearest pig farm by anti-hepatitis E virus IgG ratio

\begin{tabular}{|c|c|c|c|c|c|c|c|}
\hline \multirow[b]{2}{*}{ Age group (years) } & \multicolumn{3}{|c|}{ Positive or borderline anti-HEV IgG ratio ${ }^{a}$} & \multicolumn{3}{|c|}{ Negative anti-HEV IgG ratio $^{\text {b }}$} & \multirow[b]{2}{*}{$P$-value } \\
\hline & $\bar{n}$ & Median distance $(\mathrm{m})$ & Range in distance $(\mathrm{m})^{c}$ & $\bar{n}$ & Median distance $(\mathrm{m})$ & $\overline{\text { Range in distance }(\mathrm{m})^{c}}$ & \\
\hline $20-30$ & 5 & 689 & {$[469-850]$} & 45 & 652 & {$[489-843]$} & 1.00 \\
\hline $30-40$ & 27 & 751 & {$[373-1102]$} & 152 & 581 & {$[440-872]$} & 0.16 \\
\hline $40-50$ & 83 & 702 & [416-965] & 349 & 665 & {$[441-900]$} & 0.68 \\
\hline $50-60$ & 166 & 701 & [498-955] & 495 & 674 & {$[455-901]$} & 0.28 \\
\hline $60-70$ & 352 & 748 & [517-970] & 586 & 686 & [430-938] & 0.02 \\
\hline$>=70$ & 62 & 794 & [539-1041] & 100 & 672 & [528-1004] & 0.36 \\
\hline Total & 695 & 730 & [509-969] & 1727 & 663 & [447-916] & 0.001 \\
\hline
\end{tabular}

${ }^{\mathrm{a} A n t i-H E V ~ I g G ~ r a t i o ~}>=0.90$

${ }^{\mathrm{b}}$ Anti-HEV IgG ratio $<0.90$

${ }^{\mathrm{C}}$ Range from the 25 th to the 75 th percentile of the distance from home address to nearest pig farm

in a higher proportion of proven infections and it remains positive for longer period post infection compared with the MP assay $[56,58,59,63]$.

In line with other serological studies, we found statistically significant higher seroprevalence in participants aged 50 years and older compared to $20-30$ year olds $[18,44,57,62,64]$. This higher seroprevalence in older persons might be a result of age-dependent cumulative exposure, but can also be indicative of an age-cohort because of higher pressure of infection in the past. This age-cohort effect is also demonstrated in Denmark, the United Kingdom and the United States [60, 61, 65]. The HEV seroprevalence in blood donors as well as the high number of HEV RNA-positive donors found in serological screenings suggest an increasing HEV incidence in recent years in the Netherlands $[18,66,67]$.

Proximity to pig farms and number of animals close to the home were used as proxy of potential environmental exposure to HEV. The lack of a positive association suggests that airborne spread of HEV is unlikely. Other environmental transmission routes cannot be excluded, for example through manure that may be transported to distant places or through surface water. In the Netherlands, HEV RNA has been detected in surface water samples [68]. Furthermore, a recent cross-sectional study suggests that consumption of tap water in France might be a risk factor for HEV infection [69]. Occupational exposure to pigs, which is a potential risk factor for seropositivity, was not investigated in our study since persons living or working on a farm were excluded $[44,47,70]$. Moreover, the present study was not designed to investigate the role of food-borne transmission. Presence of IgG antibodies is an indicator for HEV infection in the past and therefore suited to study exposure to HEV through the environment. Although we found no decreased risk for HEV seropositivity in participants who did not consume pork meat, this finding must be interpreted with caution because of the small numbers of participants on a diet without pork meat $(n=47,2.0 \%)$. Moreover, some of these participants might have consumed pork meat in the past. A case-control study focussing mainly on food-borne transmission among patients with acute hepatitis E infection in the Netherlands is ongoing (study period: 2015-2017).

\section{Conclusions}

In conclusion, our study showed that the HEV seroprevalence in the general population in a livestock-dense area in the south of the Netherlands was not associated with living in proximity to pig farms. The higher seroprevalence among older participants supports the assumption of cumulative lifetime exposure to hepatitis $E$ virus in the Netherlands, as well as an age-cohort because of higher pressure of infection in the past. Although it seems plausible that transmission is primarily food-borne, further research is needed to elucidate the exact sources and routes of infection.

\section{Abbreviations}

Cl: Confidence interval; GP: General practitioner; HEV: Hepatitis E virus; OR: Odds ratio; RIVM: National Institute for Public Health and the Environment (Dutch acronym); VGO: Livestock farming and neighbouring residents' health study (Dutch acronym)

\section{Acknowledgements}

The authors would like to thank Najima Lamkaraf for performing the serological analyses, Ilse Zutt and Ngoc Hoa Roosen-Chung for technical assistance, José Ferreira for statistical advice, and Agnetha Hofhuis for critically reading the manuscript.

\section{Funding}

The Livestock Farming and Neighbouring Residents' Health (VGO) study was funded by the Ministry of Health, Welfare and Sports and the Ministry of Economic Affairs of The Netherlands, and supported by a grant from the Lung Foundation Netherlands (Grant number: 3.2.11.022).

\section{Availability of data and materials}

The datasets generated during and/or analysed during the current study are not publicly available yet, due to privacy concerns and ongoing additional research. Data can be made available for peer review on reasonable request through contacting the corresponding author.

\section{Authors' contribution}

$\mathrm{AG}, \mathrm{WH}, \mathrm{FB}, \mathrm{DH}, \mathrm{CM}, \mathrm{CY}, \mathrm{LS}$ and JR participated in the design and coordination of the study; BR and JR were responsible for the virological 
assays; AG, WH, FB, SM, and LS were involved in the statistical analyses; AG, $\mathrm{WH}, \mathrm{FB}, \mathrm{DH}, \mathrm{SM}, \mathrm{CM}, \mathrm{CY}, \mathrm{BR}, \mathrm{LS}$ and JR participated in the interpretation of data and in drafting and reviewing the Manuscript. All authors read and approved the final manuscript.

\section{Competing interests}

The authors declare that they have no competing interests.

\section{Consent for publication}

Not applicable.

\section{Ethics approval and consent to participate}

The VGO study protocol was approved by the Medical Ethical Committee of the University Medical Centre Utrecht (file number: NL45307.041.13). All participants signed informed consent. Medical information and address records were kept separated at all times by using a Trusted Third Party (Stichting Informatie Voorziening Zorg, Houten).

\section{Author details}

${ }^{1}$ National Institute for Public Health and the Environment (RIVM), Bilthoven, The Netherlands. ${ }^{2}$ Institute for Risk Assessment Sciences, IRAS, Utrecht University, Utrecht, The Netherlands. ${ }^{3}$ Netherlands Institute for Health Services Research (NIVEL), Utrecht, The Netherlands.

\section{Received: 5 October 2016 Accepted: 22 December 2016}

\section{Published online: 05 January 2017}

\section{References}

1. Lewis HC, Boisson S, ljaz S, Hewitt K, Ngui SL, Boxall E, Teo CG, Morgan D. Hepatitis E in England and Wales. Emerg Infect Dis. 2008;14(1):165-7.

2. Kantala T, Maunula L, von Bonsdorff CH, Peltomaa J, Lappalainen M. Hepatitis E virus in patients with unexplained hepatitis in Finland. J Clin Virol. 2009:45(2):109-13.

3. Mansuy JM, Abravanel F, Miedouge M, Mengelle C, Merviel C, Dubois M, Kamar N, Rostaing L, Alric L, Moreau J, et al. Acute hepatitis E in south-west France over a 5-year period. J Clin Virol. 2009;44(1):74-7.

4. Perez-Gracia MT, Mateos Lindemann ML, Caridad Montalvo Villalba M. Hepatitis E: current status. Rev Med Virol. 2013;23(6):384-98.

5. Stroffolini T, Rapicetta M, Chionne P, Esvan R, Madonna E, Lombardo F, Toccaceli F, Pisani G, Ciccaglione A, Bortolotti F. Evidence for the presence of autochthonous (locally acquired) cases of acute hepatitis E virus infections in Italy since the 80s. Eur J Intern Med. 2015;26(5):348-50.

6. Tohme RA, Drobeniuc J, Sanchez R, Heseltine G, Alsip B, Kamili S, Hu DJ, Guerra F, Teshale EH. Acute hepatitis associated with autochthonous hepatitis E virus infection-San Antonio, Texas, 2009. Clin Infect Dis. 2011;53(8):793-6.

7. Ruggeri FM, Di Bartolo I, Ponterio E, Angeloni G, Trevisani M, Ostanello F. Zoonotic transmission of hepatitis $E$ virus in industrialized countries. New Microbiol. 2013:36(4):331-44.

8. Echevarria JM. Autochthonous Hepatitis E virus infection in Europe: a matter of concern for public health? J Clin Transl Hepatol. 2014;2(1):7-14.

9. Aggarwal R, Naik S. Epidemiology of hepatitis E: current status. J Gastroenterol Hepatol. 2009;24(9):1484-93.

10. Khuroo MS, Khuroo MS. Hepatitis E: an emerging global disease - from discovery towards control and cure. J Viral Hepat. 2015;23(2):68-79.

11. Koot H, Hogema BM, Koot M, Molier M, Zaaijer HL. Frequent hepatitis E in the Netherlands without traveling or immunosuppression. J Clin Virol. 2015:62:38-40.

12. Lucarelli C1, Spada E, Taliani G, Chionne P, Madonna E, Marcantonio C, Pezzotti P, Bruni R, La Rosa G, Pisani G, Dell'Orso L, Ragone K, Tomei C, Ciccaglione AR. High prevalence of anti-hepatitis $E$ virus antibodies among blood donors in central Italy, February to March 2014. Euro Surveill. 2016; 21(30). doi:10.2807/1560-7917.ES.2016.21.30.30299.

13. Turner J, Godkin A, Neville P, Kingham J, Ch'ng CL. Clinical characteristics of hepatitis E in a "Non-Endemic" population. J Med Virol. 2010;82(11):1899-902.

14. Arends JE, Ghisetti V, Irving W, Dalton HR, Izopet J, Hoepelman Al, Salmon D. Hepatitis E: An emerging infection in high income countries. J Clin Virol. 2014;59(2):81-8

15. Kamar N, Dalton HR, Abravanel F, Izopet J. Hepatitis E virus infection. Clin Microbiol Rev. 2014;27(1):116-38.

16. Kamar N, Bendall R, Legrand-Abravanel F, Xia NS, ljaz S, Izopet J, Dalton HR. Hepatitis E. Lancet. 2012;379(9835):2477-88.
17. Dalton HR, Bendall R, ljaz S, Banks M. Hepatitis E: an emerging infection in developed countries. Lancet Infect Dis. 2008;8(11):698-709.

18. Slot E, Hogema BM, Riezebos-Brilman A, Kok TM, Molier M, Zaaijer HL. Silent hepatitis E virus infection in Dutch blood donors, 2011 to 2012. Euro Surveill. 2013;18(31).

19. Juhl D, Baylis SA, Blumel J, Gorg S, Hennig H. Seroprevalence and incidence of hepatitis E virus infection in German blood donors. Transfusion. 2014;54(1):49-56.

20. Fischer C, Hofmann M, Danzer M, Hofer K, Kaar J, Gabriel C. Seroprevalence and Incidence of hepatitis $\mathrm{E}$ in blood donors in Upper Austria. PLoS One. 2015;10(3):e0119576.

21. Mansuy JM, Saune K, Rech H, Abravanel F, Mengelle C, LH S, Destruel F, Kamar N, Izopet J. Seroprevalence in blood donors reveals widespread, multi-source exposure to hepatitis E virus, southern France, October 2011. Euro Surveill. 2015:20(19):27-34.

22. Hartl J, Otto B, Madden RG, Webb G, Woolson KL, Kriston L, Vettorazzi E, Lohse AW, Dalton HR, Pischke S. Hepatitis E Seroprevalence in Europe: A Meta-Analysis. Viruses. 2016;8(8). doi:10.3390/v8080211.

23. Perez-Gracia MT, Garcia M, Suay B, Mateos-Lindemann ML. Current knowledge on hepatitis E. J Clin Transl Hepatol. 2015;3(2):117-26.

24. Smith DB, Simmonds $P$, Jameel S, Emerson SU, Harrison TJ, Meng XJ, Okamoto H, Van der Poel WH, Purdy MA. Consensus proposals for classification of the family Hepeviridae. J Gen Virol. 2014;95(Pt 10):2223-32.

25. Khuroo MS. Discovery of hepatitis $E$ : the epidemic non-A, non-B hepatitis 30 years down the memory lane. Virus Res. 2011;161(1):3-14.

26. Dalton HR, Hunter JG, Bendall RP. Hepatitis E. Curr Opin Infect Dis. 2013:26(5):471-8

27. Pavio N, Meng XJ, Doceul V. Zoonotic origin of hepatitis E. Curr Opin Virol. 2015;10:34-41.

28. Van der Poel WH. Food and environmental routes of Hepatitis E virus transmission. Curr Opin Virol. 2014;4:91-6.

29. Lee GH, Tan BH, Teo EC, Lim SG, Dan YY, Wee A, Aw PP, Zhu Y, Hibberd ML, Tan CK, et al. Chronic infection with camelid hepatitis E virus in a liver transplant recipient who regularly consumes camel meat and milk. Gastroenterology. 2016;150(2):355-7. e353.

30. Adlhoch C, Avellon A, Baylis SA, Ciccaglione AR, Couturier E, de Sousa R, Epstein J, Ethelberg S, Faber M, Feher A, et al. Hepatitis E virus: Assessment of the epidemiological situation in humans in Europe, 2014/15. J Clin Virol. 2016;82:9-16.

31. Bouwknegt M, Rutjes SA, Reusken CB, Stockhofe-Zurwieden N, Frankena K de Jong MC, de Roda Husman AM, Poel WH. The course of hepatitis E virus infection in pigs after contact-infection and intravenous inoculation. BMC Vet Res. 2009:5:7.

32. Rutjes SA, Lodder WJ, Bouwknegt M, de Roda Husman AM. Increased hepatitis $E$ virus prevalence on Dutch pig farms from 33 to $55 \%$ by using appropriate internal quality controls for RT-PCR. J Virol Methods. 2007:143(1):112-6.

33. Bouwknegt $M$, Lodder-Verschoor F, van der Poel WH, Rutjes SA, de Roda Husman AM. Hepatitis E virus RNA in commercial porcine livers in The Netherlands. J Food Prot. 2007;70(12):2889-95

34. Berto A, Martelli F, Grierson S, Banks M. Hepatitis E virus in pork food chain, United Kingdom, 2009-2010. Emerg Infect Dis. 2012;18(8):1358-60.

35. Di Bartolo I, Diez-Valcarce M, Vasickova P, Kralik P, Hernandez M, Angeloni G, Ostanello F, Bouwknegt M, Rodriguez-Lazaro D, Pavlik I, et al. Hepatitis E virus in pork production chain in Czech Republic, Italy, and Spain, 2010. Emerg Infect Dis. 2012;18(8):1282-9.

36. Berto A, Grierson S, Hakze-van der Honing R, Martelli F, Johne R, Reetz J, Ulrich RG, Pavio N, Van der Poel WH, Banks M. Hepatitis E virus in pork liver sausage, France. Emerg Infect Dis. 2013;19(2):264-6.

37. Li TC, Chijiwa K, Sera N, Ishibashi T, Etoh Y, Shinohara Y, Kurata Y, Ishida M, Sakamoto S, Takeda N, et al. Hepatitis E virus transmission from wild boar meat. Emerg Infect Dis. 2005;11(12):1958-60.

38. Tei S, Kitajima N, Takahashi K, Mishiro S. Zoonotic transmission of hepatitis E virus from deer to human beings. Lancet. 2003:362(9381):371-3.

39. Renou C, Roque-Afonso AM, Pavio N. Foodborne transmission of hepatitis $E$ virus from raw pork liver sausage, France. Emerg Infect Dis. 2014;20(11):1945-7.

40. Riveiro-Barciela M, Minguez B, Girones R, Rodriguez-Frias F, Quer J, Buti M. Phylogenetic demonstration of hepatitis $\mathrm{E}$ infection transmitted by pork meat ingestion. J Clin Gastroenterol. 2015;49(2):165-8.

41. Pavio N, Meng XJ, Renou C. Zoonotic hepatitis E: animal reservoirs and emerging risks. Vet Res. 2010;41(6):46. 
42. Withers MR, Correa MT, Morrow M, Stebbins ME, Seriwatana J, Webster WD, Boak MB, Vaughn DW. Antibody levels to hepatitis E virus in North Carolina swine workers, non-swine workers, swine, and murids. AmJTrop Med Hyg. 2002;66(4):384-8.

43. Aggarwal R, Jameel S. Hepatitis E. Hepatology. 2011;54(6):2218-26.

44. Drobeniuc J, Favorov MO, Shapiro CN, Bell BP, Mast EE, Dadu A, Culver D, larovoi P, Robertson BH, Margolis HS. Hepatitis E virus antibody prevalence among persons who work with swine. J Infect Dis. 2001;184(12):1594-7.

45. Bouwknegt M, Engel B, Herremans MM, Widdowson MA, Worm HC, Koopmans MP, Frankena K, de Roda Husman AM, De Jong MC, Van Der Poel WH. Bayesian estimation of hepatitis $\mathrm{E}$ virus seroprevalence for populations with different exposure levels to swine in The Netherlands. Epidemiol Infect. 2008;136(4):567-76.

46. Chaussade H, Rigaud E, Allix A, Carpentier A, Touze A, Delzescaux D, Choutet P, Garcia-Bonnet N, Coursaget P. Hepatitis E virus seroprevalence and risk factors for individuals in working contact with animals. J Clin Virol. 2013;58(3):504-8.

47. Krumbholz A, Joel S, Dremsek P, Neubert A, Johne R, Durrwald R, Walther M, Muller TH, Kuhnel D, Lange J, et al. Seroprevalence of hepatitis E virus (HEV) in humans living in high pig density areas of Germany. Med Microbiol Immunol. 2014;203(4):273-82.

48. van der Hoek W, Morroy G, Renders NH, Wever PC, Hermans MH, Leenders AC, Schneeberger PM. Epidemic Q fever in humans in the Netherlands. Adv Exp Med Biol. 2012;984:329-64.

49. Borlee F, Yzermans CJ, van Dijk CE, Heederik D, Smit LA. Increased respiratory symptoms in COPD patients living in the vicinity of livestock farms. Eur Respir J. 2015;46(6):1605-14.

50. Borlee F, Yzermans J, Krop E, Aalders B, Zock JP, Van Dijk C, Maassen K, Schellevis F, Heederik D, Smit LAM. Assessment of asthma and COPD prevalence: a comparison between three different data sources. In: American Thoracic Society, editor. B48 asthma: insights from the bench, genetics, and epidemiology. 2016. p. A3694.

51. Smit LA, Hooiveld M, van der Sman-de Beer F, Opstal-van Winden AW, Beekhuizen J, Wouters IM, Yzermans CJ, Heederik D. Air pollution from livestock farms, and asthma, allergic rhinitis and COPD among neighbouring residents. Occup Environ Med. 2014;71(2):134-40.

52. Smit LA, van der Sman-de Beer F, Opstal-van Winden AW, Hooiveld M, Beekhuizen J, Wouters IM, Yzermans J, Heederik D. Q fever and pneumonia in an area with a high livestock density: a large population-based study. PLoS One. 2012;7(6):e38843.

53. Maassen K, Heederik D, IJzermans J, Hagenaars T, van der Hoek W. Livestock Farming and Neighbouring Residents' Health [in Dutch]. Bilthoven: National Institute for Public Health and the Environment; 2016.

54. Lapa D, Capobianchi MR, Garbuglia AR. Epidemiology of Hepatitis E Virus in European Countries. Int J Mol Sci. 2015;16(10):25711-43.

55. Wenzel JJ, Preiss J, Schemmerer M, Huber B, Jilg W. Test performance characteristics of Anti-HEV IgG assays strongly influence hepatitis $E$ seroprevalence estimates. J Infect Dis. 2013;207(3):497-500.

56. Schnegg A, Burgisser P, Andre C, Kenfak-Foguena A, Canellini G, Moradpour D, Abravanel F, Izopet J, Cavassini M, Darling KE. An analysis of the benefit of using HEV genotype 3 antigens in detecting anti-HEV IgG in a European population. PLoS One. 2013;8(5):e62980.

57. Faber MS, Wenzel JJ, Jilg W, Thamm M, Hohle M, Stark K. Hepatitis E virus seroprevalence among adults, Germany. Emerg Infect Dis. 2012;18(10):1654-7.

58. Bendall $R$, Ellis $V$, ljaz $S$, Ali $R$, Dalton $H$. A comparison of two commercially available anti-HEV lgG kits and a re-evaluation of anti-HEV IgG seroprevalence data in developed countries. J Med Virol. 2010;82(5):799-805.

59. Mansuy JM, Bendall R, Legrand-Abravanel F, Saune K, Miedouge M, Ellis V, Rech H, Destruel F, Kamar N, Dalton HR, et al. Hepatitis E virus antibodies in blood donors, France. Emerg Infect Dis. 2011;17(12):2309-12.

60. Xu C, Wang RY, Schechterly CA, Ge S, Shih JW, Xia NS, Luban NL, Alter HJ. An assessment of hepatitis E virus (HEV) in US blood donors and recipients: no detectable HEV RNA in 1939 donors tested and no evidence for HEV transmission to 362 prospectively followed recipients. Transfusion. 2013:53:2505-11.

61. Christensen PB, Engle RE, Hjort C, Homburg KM, Vach W, Georgsen J, Purcell $\mathrm{RH}$. Time trend of the prevalence of hepatitis $\mathrm{E}$ antibodies among farmers and blood donors: a potential zoonosis in Denmark. Clin Infect Dis. 2008:47(8):1026-31.

62. Verhoef L, Koopmans M, Duizer E, Bakker J, Reimerink J, Van Pelt W. Seroprevalence of hepatitis $E$ antibodies and risk profile of HEV seropositivity in The Netherlands, 2006-2007. Epidemiol Infect. 2012;140(10):1838-47.
63. Avellon A, Morago L, Garcia-Galera del Carmen M, Munoz M, Echevarria JM. Comparative sensitivity of commercial tests for hepatitis E genotype 3 virus antibody detection. J Med Virol. 2015;87(11):1934-9.

64. Lagler H, Poeppl W, Winkler H, Herkner H, Faas A, Mooseder G, Burgmann $H$. Hepatitis E virus seroprevalence in Austrian adults: a nationwide crosssectional study among civilians and military professionals. PLoS One. 2014;9(2):e87669

65. ljaz S, Vyse AJ, Morgan D, Pebody RG, Tedder RS, Brown D. Indigenous hepatitis $E$ virus infection in England: more common than it seems. J Clin Virol. 2009;44(4):272-6.

66. Hogema BM, Molier M, Slot E, Zaaijer HL. Past and present of hepatitis E in the Netherlands. Transfusion. 2014;54(12):3092-6.

67. Hogema BM, Molier M, Sjerps M, de Waal M, van Swieten P, van de Laar T, Molenaar-de Backer M, Zaaijer HL. Incidence and duration of hepatitis $E$ virus infection in Dutch blood donors. Transfusion. 2016;56(3):722-8.

68. Rutjes SA, Lodder WJ, Lodder-Verschoor F, van den Berg HH, Vennema H, Duizer E, Koopmans M, de Roda Husman AM. Sources of hepatitis E virus genotype 3 in The Netherlands. Emerg Infect Dis. 2009;15(3):381-7.

69. Mansuy JM, Gallian P, Dimeglio C, Saune K, Arnaud C, Pelletier B, Morel P, Legrand D, Tiberghien P, Izopet J. A nationwide survey of hepatitis $E$ viral infection in French blood donors. Hepatology. 2016;63(4):1145-54.

70. Galiana C, Fernandez-Barredo S, Garcia A, Gomez MT, Perez-Gracia MT. Occupational exposure to hepatitis E virus (HEV) in swine workers. AmJTrop Med Hyg. 2008;78(6):1012-5.

\section{Submit your next manuscript to BioMed Central and we will help you at every step:}

- We accept pre-submission inquiries

- Our selector tool helps you to find the most relevant journal

- We provide round the clock customer support

- Convenient online submission

- Thorough peer review

- Inclusion in PubMed and all major indexing services

- Maximum visibility for your research

Submit your manuscript at www.biomedcentral.com/submit
Biomed Central 